\title{
BMJ Open Ambulance dispatch of older patients following primary and secondary telephone triage in metropolitan Melbourne, Australia: a retrospective cohort study
}

\author{
Kathryn Eastwood (D) ,1,2 Dhanya Nambiar (D) , ${ }^{1}$ Rosamond Dwyer, ${ }^{1}$ \\ Judy A Lowthian (D) , ${ }^{1,3}$ Peter Cameron (D) , ${ }^{1}$ Karen Smith (1) ${ }^{1,2}$
}

To cite: Eastwood K, Nambiar D, Dwyer R, et al. Ambulance dispatch of older patients following primary and secondary telephone triage in metropolitan Melbourne, Australia: a retrospective cohort study. BMJ Open 2020;10:e042351. doi:10.1136/ bmjopen-2020-042351

- Prepublication history for this paper is available online. To view these files, please visit the journal online (http://dx.doi org/10.1136/bmjopen-2020042351).

Received 02 July 2020

Revised 14 September 2020

Accepted 06 0ctober 2020

Check for updates

(C) Author(s) (or their employer(s)) 2020. Re-use permitted under CC BY-NC. No commercial re-use. See rights and permissions. Published by BMJ.

${ }^{1}$ Department of Epidemiology and Preventive Medicine,

Monash University, Melbourne,

Victoria, Australia

${ }^{2}$ Centre for Research and

Evaluation, Ambulance Victoria,

Doncaster, Victoria, Australia

${ }^{3}$ Bolton Clarke Research

Institute, Bolton Clarke,

Bentleigh, Victoria, Australia

Correspondence to

Dr Kathryn Eastwood;

kathryn.eastwood@monash.edu

\section{ABSTRACT}

Background Most calls to ambulance result in emergency ambulance dispatch (direct dispatch) following primary telephone triage. Ambulance Victoria uses clinician-led secondary telephone triage for patients identified as lowacuity during primary triage to refer them to alternative care pathways; however, some are returned for ambulance dispatch (secondary dispatch). Older adult patients are frequent users of ambulance services; however, little is known about the appropriateness of subsequent secondary dispatches.

Objectives To examine the appropriateness of secondary dispatch through a comparison of the characteristics and ambulance outcomes of older patients dispatched an emergency ambulance via direct or secondary dispatch.

Design A retrospective cohort study of ambulance patient data between September 2009 and June 2012 was conducted.

Setting The secondary telephone triage service operated in metropolitan Melbourne, Victoria, Australia during the study period.

Participants There were 90086 patients included aged 65 years and over who had an emergency ambulance dispatch via direct or secondary dispatch with one of the five most common secondary dispatch paramedic diagnoses.

Main outcome measures Descriptive analyses compared characteristics, treatment and transportation rates between direct and secondary dispatch patients. Results The dispatch groups were similar in demographics, vital signs and hospital transportation rates. However, secondary dispatch patients were half as likely to be treated by paramedics (OR 0.51 ; $\mathrm{Cl} 0.48$ to 0.55 ; $\mathrm{p}<0.001)$. Increasing age was associated with decreasing treatment $(p<0.005)$ and increasing transportation rates $(p<0.005)$.

Conclusion Secondary triage could identify patients who would ultimately be transported to an emergency department. However, the lower paramedic treatment rates suggest many secondary dispatch patients may have been suitable for referral to alternative low-acuity transport or referral options.

\section{Strengths and limitations of this study}

- This is the first study to investigate the appropriateness of secondary dispatch of older patients by comparing patients entering the secondary dispatch pathway to those directly dispatched.

- This study used a range of independently derived outcomes to assess appropriateness to avoid the bias that can result when relying on expert opinion.

- A significant difference existed in the population sizes between the secondary and direct dispatch pathways; therefore, analysis was limited to the most common paramedic diagnostic categories to ensure comparability between the two groups and meaningful results.

\section{INTRODUCTION}

To manage increasing demand for emergency ambulances, Ambulance Victoria (AV) introduced a secondary telephone triage service called the Referral Service in 2003. Cases identified as low-acuity by Triple Zero (000-the Australian emergency telephone number) primary triage are transferred for secondary triage and diversion to alternative care pathways while all other cases are sent for ambulance dispatch (direct dispatch). ${ }^{1}$ In 2018-2019, this secondary triage service diverted $15.6 \%$ (114 589 cases) of AV's workload to alternative healthcare providers or home care, or following secondary triage, returned other cases for emergency ambulance dispatch (secondary dispatch). Research has shown that secondary dispatch cases had paramedic treatment rates similar to direct dispatch cases, ${ }^{2}$ and were significantly more appropriate for the emergency department (ED). ${ }^{3}$ Older adult patients are frequent users of ambulance services ${ }^{4}$; however, little is known about their secondary triage usage 
and the appropriateness of the referral of these patients back into the emergency care pathways.

In many high-income countries, the ageing population is a major driver of the increasing demand for emergency ambulance services and EDs. ${ }^{4}$ In Victoria, Australia, persons aged 70 years and older have up to four times the ambulance attendance rate of younger groups and persons 85 years and older have an eightfold increase. ${ }^{46}$ Unnecessary ambulance and ED presentations can place vulnerable older patients at risk of adverse outcomes including exposure to infection, delirium, social disruption and discomfort in the ED environment. A proportion of these presentations may be avoidable with improved use of existing community health and transportation resources and better advance care planning. ${ }^{7-9}$ However, there is no central access point to out-of-hours primary care services in Victoria and some, like nonemergency ambulance transportation, are not accessible to the general public without a referral from healthcare services. As a result, many people seek assistance from AV.

Decisions about alternative care pathways in the Referral Service are made by triaging nurses and paramedics using a condition-specific computer-based questioning algorithm to further elucidate the presenting problem. Cases undergoing secondary triage are low-acuity cases with historically low rates of paramedic treatment, transportation to hospital and re-presentation to 000 within 24 hours. $^{10}$ Beyond the usual challenges of telephone triage, such as the lack of visual cues and dependency on adequate caller and call-taker communication, factors such as medical comorbidity, frailty, cognitive impairment or social isolation can heighten the complexity of the patient assessment. This may result in higher unnecessary referrals for emergency ambulance dispatch. ${ }^{46}$

This study aims to examine the appropriateness of secondary dispatch through a comparison of the characteristics and ambulance outcomes of older patients dispatched an emergency ambulance via direct or secondary dispatch.

\section{METHOD}

\section{Study design}

A retrospective cohort study was conducted of AV electronic patient care records (ePCR), the Victorian Ambulance Clinical Information System and Referral Service records between 1 September 2009 and 30 June 2012.

\section{Patient and public involvement statement}

It was not appropriate or possible to involve patients or the public in the design, or conduct, or reporting, or dissemination plans of our research.

\section{Study setting}

$\mathrm{AV}$ is the sole emergency medical service provider in the state of Victoria, Australia. Cases included in this study occurred in metropolitan Melbourne, the capital city of
Victoria and Australia's second largest city comprising over four million people in 2012. ${ }^{112}$

AV operates a two-tiered medical response system using advanced life support (ALS) paramedics as the base qualification level, and intensive care paramedics with a broader skill set. ${ }^{1}$ The Advanced Medical Priority Dispatch System and an AV formulated service allocation matrix is used to determine which skill set is required to respond to calls for medical assistance. ${ }^{1}$ In addition to emergency ambulances, AV operates the 'Referral Service' 24 hours per day, 7 days per week. This service provides a clinician-led secondary telephone triage using a computer-based triage algorithm to guide the triage process to determine case disposition. ${ }^{1}$ The decision-making process lies solely with the triaging nurse or paramedic and no consultation occurs with any primary care service or ED clinicians. Aside from the computer-based triaging algorithm, the only other tool that can be employed in the decisionmaking process is the use of patient care plans that are created for patients with chronic psychiatric illness who are frequent users of 000 and the ED. The final dispositions include self-care advice, a recommendation to selfpresent at a community-based health service or hospital, dispatch of one of a range of alternative service providers such as home-visiting doctors, nurses or hospital outreach programmes, or dispatch of a non-emergency or emergency ambulance. When returning cases for emergency ambulance dispatch, the urgency of the ambulance dispatch is determined at the discretion of the triaging clinician. Cases can be dispatched as high acuity, resulting in a lights-and-sirens immediate response, moderateacuity being expedient dispatch with ambulance adherence to road rules, or low-acuity, whereby an ambulance is dispatched when available and it can be diverted to a more urgent case if required. The Referral Service has been described in detail elsewhere. ${ }^{1}$

\section{Data sources}

ePCRs were extracted by the data custodian for people aged 65 years and over who were attended by an emergency ambulance within metropolitan Melbourne during the study period. Linked Referral Service records of cases referred for secondary ambulance dispatch were also obtained. All data were deidentified by AV prior to sending to the researchers. To ensure adequate sample size and comparability between the two groups, analysis was limited to the most common paramedic diagnostic categories (broad symptom groups) for older patients in the secondary dispatch pathway cohort (being the smaller group). Direct dispatch cases with the same paramedic diagnosis were extracted to allow for comparison between the groups.

\section{Inclusion criteria}

- AV cases involving patients 65 years and older who were attended by emergency ambulance paramedics in metropolitan Melbourne between September 2009 and June 2012. 
- Patients attended by emergency ambulance following direct ambulance dispatch or secondary ambulance dispatch.

- Paramedic diagnostic category recorded on the ePCR was one of the top five paramedic diagnostic categories for the secondary dispatch group.

\section{Exclusion criteria}

- Patients who were dead on arrival or died at scene were excluded from further analysis, as deceased adult patients are not transported by the ambulance service.

- Cases where ePCRs were not available.

\section{Outcome measures}

Two previously used indicators of the appropriateness of prehospital triage and emergency ambulance services, paramedic treatment and transport to hospital, were used in this study. ${ }^{10} 1314$

'Paramedic treatment' was derived from indicators that ALS-level paramedic treatment was provided. In Victoria, non-emergency ambulance officers provide Basic Life Support (BLS) care, including external cardiac monitoring, extrication and manual handling assistance, basic first aid and provision of a small range of drugs to manage patients. Therefore, in Victoria low-acuity cases that require transportation to an ED may be appropriate for referral to a non-emergency ambulance following secondary telephone triage. Where BLS treatment or only reassurance and general care to ensure comfort and basic assistance occurred, or where an intravenous line was inserted and not subsequently used for drug or fluid administration, the case was classified as not having received ALS treatment, and therefore not having 'paramedic treatment'. Paramedic treatment therefore consisted of drug or crystalloid administration, airway management (including airway adjuncts), oxygen therapy and management of behavioural emergencies including chemical or physical restraint.

'Paramedic transport' occurred when a patient was transported to hospital by the emergency ambulance that was dispatched. Paramedics in Victoria have the option to recommend other care pathways such as self-presentation to local General Practitioners (GPs) or to provide care and advice prior to leaving patients at home. Therefore, patients transported to hospital by the attending emergency ambulance were considered to be appropriate for emergency ambulance dispatch in this study.

\section{Variables of interest}

A range of exposure variables were investigated against the outcomes variables of paramedic treatment and transport (table 1).

\section{Statistical analysis}

Descriptive statistics were used to compare patient and dispatch characteristics between the direct and secondary triage dispatch groups, and to calculate the proportion of patients treated and transported within each final paramedic diagnostic group. Multivariable
Table 1 Definitions of the variables of interest

\begin{tabular}{|c|c|}
\hline $\begin{array}{l}\text { Variables of } \\
\text { interest }\end{array}$ & Definition \\
\hline Age & $\begin{array}{l}\text { The biological age of the patient at the time of } \\
\text { the interaction with AV. Categorised into } 5 \text {-year } \\
\text { increments to } 90 \text { years. }\end{array}$ \\
\hline Gender & $\begin{array}{l}\text { The biological sex of the patient. Categorised as male } \\
\text { and female. }\end{array}$ \\
\hline $\begin{array}{l}\text { Primary } \\
\text { diagnosis }\end{array}$ & $\begin{array}{l}\text { The final paramedic diagnosis category recorded in } \\
\text { ePCR following paramedic clinical assessment. These } \\
\text { are a broad symptom groups. }\end{array}$ \\
\hline $\begin{array}{l}\text { Local } \\
\text { Government } \\
\text { Area (LGA) }\end{array}$ & $\begin{array}{l}\text { Identified through patient residential postcodes. } \\
\text { The median income for each LGA reported by the } \\
\text { Australian Bureau of Statistics was used to compare } \\
\text { the LGA median income to the median income of all } \\
\text { metropolitan Melbourne in } 2011 / 2012 \text { as a proxy for } \\
\text { socioeconomic status. LGAs were classed has being } \\
\text { 'above' or 'below' the median income of metropolitan } \\
\text { Melbourne. }\end{array}$ \\
\hline
\end{tabular}

Vital signs The physiological measurements obtained by paramedics. Vital signs were classed as 'normal' or 'abnormal (low or high)' as indicated below. The vital signs were categorised as follows:

Initial pulse rate (beats/min): 0-59 (abnormal - low), 60-99 (normal) and 100-248 (abnormal - high)

Systolic blood pressure: 0-99 (abnormal - low), 100139 (normal) and 140 and above (abnormal - high)

Glasgow Coma Scale: 3-9 (abnormal), 10-14 (abnormal) and 15 (normal)

Time of day Aligned with the common paramedic 'day-shift 'of 0700-1700 hours or 'night-shift' of 1700-0700 hours

$\begin{array}{ll}\begin{array}{l}\text { Weighted } \\ \text { Charlson }\end{array} & \begin{array}{l}\text { The WCCI is a method of categorising comorbidities } \\ \text { using the International Classification of Diseases }\end{array} \\ \begin{array}{l}\text { Comorbidity } \\ \text { Index }\end{array} & \begin{array}{l}\text { diagnosis codes. The comorbidity categories are } \\ \text { weighted from } 1 \text { to } 6 \text { based on the adjusted risk of } \\ \text { (WCCI) }\end{array} \\ & \begin{array}{ll}\text { mortality or resource use. The comorbidity score is } \\ \text { the sum of all the weights. The WCCl was calculated } \\ \text { and categorised using methods published by }\end{array} \\ & \begin{array}{l}\text { Charlson et al. } .^{23} \\ \text { Highest }\end{array} \\ \begin{array}{ll}\text { Code 1: immediate emergency ambulance dispatch } \\ \text { code }\end{array} & \begin{array}{l}\text { using lights and sirens; arrival at the case within } 15 \\ \text { min. }\end{array}\end{array}$

Code 2: immediate emergency ambulance dispatch with no lights or sirens. Obey all road rules and arrive within 25-30 min.

Code 3: low-acuity dispatches, arrival to the patient within $60 \mathrm{~min}$. Ambulance will be diverted if a more acute case arises closer to them

\begin{tabular}{|c|c|}
\hline \multirow[t]{5}{*}{$\begin{array}{l}\text { Initial pain } \\
\text { score }\end{array}$} & $\begin{array}{l}\text { During clinical assessment, patients were asked } \\
\text { to rank any pain on a continuous scale of } 0-10 \text {, } \\
\text { categorised as: }\end{array}$ \\
\hline & 0 (no pain) \\
\hline & 1-2 (mild: does not require treatment) \\
\hline & 3-6 (medium: requires treatment) and \\
\hline & 7-10 (high: requires treatment) \\
\hline
\end{tabular}

ePCR, electronic patient care record.

random-effects logistic regression was used to determine the association between secondary ambulance dispatch cases (vs direct ambulance dispatch cases) 


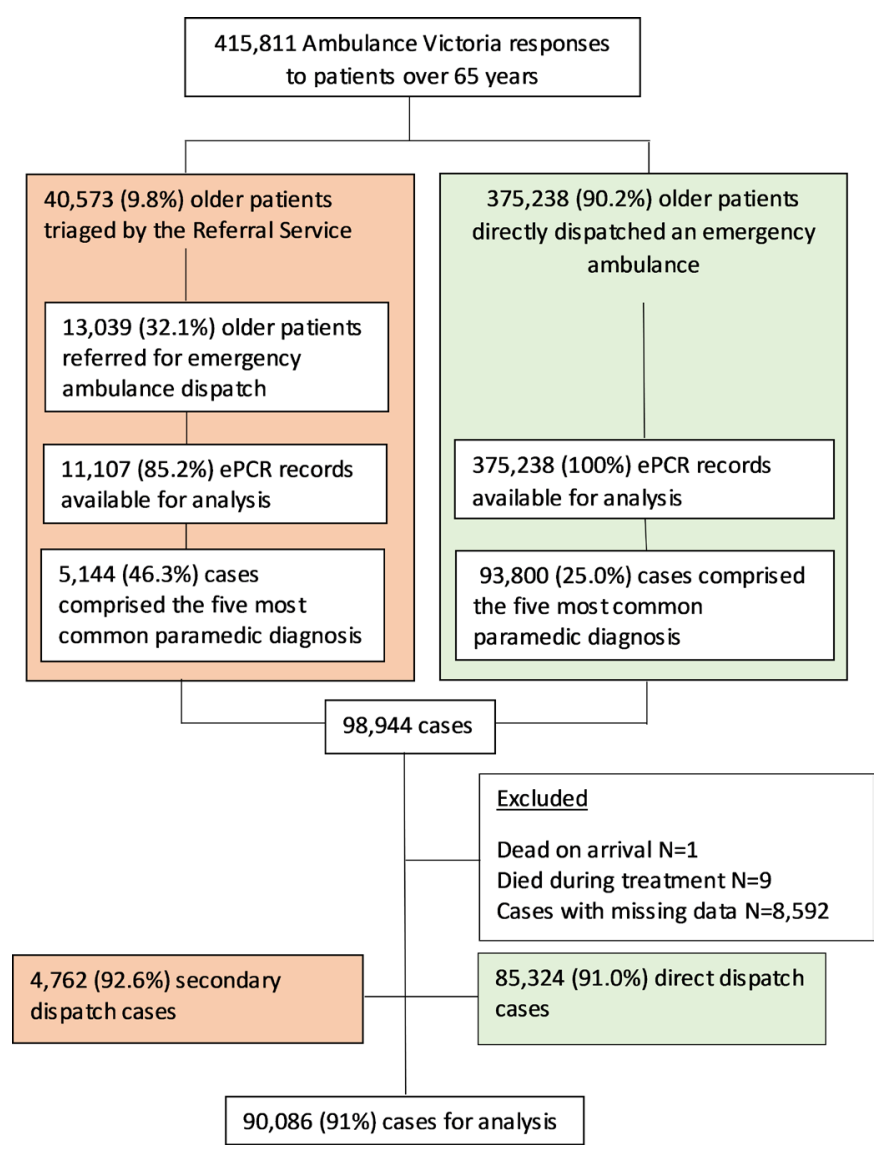

Figure 1 Distribution of older patients to direct and secondary dispatch pathways and study inclusion. ePCR, electronic patient care record.

and treatment and transport rates, reported as unadjusted and adjusted OR. Given the large sample size, in addition to $p$ values below 0.05 being considered statistically significant, effect sizes were also used to interpret the clinical significance of the results. All analyses were conducted using Stata V.15.0 (StataCorp LLC).

\section{RESULTS}

Between 1 September 2009 and 30 June 2012, AV attended 415811 cases involving patients over 65 years of age across metropolitan Melbourne. Figure 1 shows the distribution of older patients who received either a direct or secondary ambulance dispatch. Overall, $90.2 \%$ of older patients were directly dispatched an emergency ambulance after 000 primary triage with the remainder referred to secondary triage. Almost a third $(32.1 \%)$ of older patients who underwent a secondary triage were subsequently referred for secondary dispatch. Older patients from both dispatch pathways with any of the five most frequent paramedic diagnoses from secondary dispatch cases comprised the study population. Therefore, after excluded cases, there were $90086(91 \%)$ cases eligible for further analysis. The distribution of cases from both dispatch pathways was pain $(71.1 \%)$, gastrointestinal problem $(10.5 \%)$, dizziness $(6.8 \%)$, urinary tract infection (UTI) $(6.2 \%)$ and febrile illness ( $5.4 \%$; table 2 ).

\section{Group characteristics}

Comparison of the direct and secondary ambulance dispatch pathways found the groups were similar across patient demographics, vital signs and case characteristics (table 2). The largest variation between the dispatch pathways were observed in paramedic diagnostic group distribution, initial pain scores, dispatch code categories and treatment.

The pain and gastrointestinal disorders paramedic diagnostic groups had the highest proportion of patients, respectively, for both dispatch pathways; however, the distribution of patients to the remaining diagnoses varied. The pain diagnostic group comprised a range of generalised pain complaints that could not be classified to more specific diagnostic groups like back, chest or abdominal pain. More patients in the secondary dispatch pathway rated their pain as severe (7-10 out of 10) compared with patients in the direct dispatch pathway (moderate pain: 4-6 out of 10). A greater proportion of patients dispatched an ambulance following secondary triage were dispatched a Code 3 low-acuity emergency ambulance response whereas the majority of direct dispatch patients were dispatched a Code 1 high-acuity response.

\section{Ambulance appropriateness}

In this study, appropriateness for emergency ambulance dispatch was measured by whether ALS-level paramedic treatment was provided or whether the attending paramedics subsequently transported patient to the ED. Overall, the rate of paramedic treatment in older patients was lower than the average rate of $55.5 \%$ in all AV patients, ${ }^{10}$ particularly for secondary dispatch patients of whom only a third were treated. While this suggests the appropriateness for ambulance was relatively low, the paramedic transportation rates were high, and similar between the groups.

Paramedic treatment and transport rates for the two dispatch pathways were stratified by paramedic diagnosis to determine if appropriateness varied between these diagnoses. A higher proportion of patients were treated for pain, dizziness and febrile illness in the direct dispatch group; however, only the pain diagnosis had treatment rates similar to the average AV treatment rate (table 3). Transport rates were comparable between the two groups across the diagnoses.

Using random-effects logistic regression models, and adjusting for patient demographics and case characteristics, secondary dispatch patients were almost half as likely to be treated compared with direct dispatch patients; however, there was no difference in the likelihood of transportation to hospital (table 4).

Over the age of 75 years, the odds of being treated decreased with age, but the likelihood of transport increased after 80 years of age. As pain scores increased, 
Table 2 Patient demographics and clinical information: direct dispatch versus secondary dispatch for all Ambulance Victoria (AV) patients over 65 years who were diagnosed with one of five common paramedic diagnoses between 2009 and 2012 ( $N=90086)$

\begin{tabular}{|c|c|c|c|c|c|c|}
\hline & \multicolumn{2}{|l|}{ Total } & \multicolumn{2}{|c|}{$\begin{array}{l}\text { Direct } \\
\text { dispatch ( } N=85 \\
\text { 324) }\end{array}$} & \multicolumn{2}{|c|}{$\begin{array}{l}\text { Secondary } \\
\text { dispatch } \\
(\mathrm{N}=4762)\end{array}$} \\
\hline & $\mathbf{N}$ & $\%$ & $\mathbf{N}$ & $\%$ & $\mathbf{N}$ & $\%$ \\
\hline \multicolumn{7}{|l|}{ Age (years) } \\
\hline $65-69$ & 13139 & 14.6 & 12458 & 15 & 681 & 14 \\
\hline $70-74$ & 14811 & 16.4 & 13954 & 16 & 857 & 18 \\
\hline $75-79$ & 17446 & 19.4 & 16503 & 19 & 943 & 20 \\
\hline $80-84$ & 19749 & 21.9 & 18693 & 22 & 1056 & 22 \\
\hline $85-89$ & 15813 & 17.6 & 14984 & 18 & 829 & 17 \\
\hline $90-107$ & 9128 & 10.1 & 8732 & 10 & 396 & 8.3 \\
\hline \multicolumn{7}{|l|}{ Gender } \\
\hline Female & 51817 & 57.5 & 49183 & 58 & 2634 & 55 \\
\hline Male & 38269 & 42.5 & 36141 & 42 & 2128 & 45 \\
\hline \multicolumn{7}{|l|}{ Normal vital signs } \\
\hline \multicolumn{7}{|l|}{ Initial pulse rate } \\
\hline $60-99 / \min$ & 72424 & 80.4 & 68470 & 80 & 3954 & 83 \\
\hline \multicolumn{7}{|c|}{ Initial systolic blood pressure } \\
\hline $100-139 \mathrm{~mm} \mathrm{Hg}$ & 34872 & 38.7 & 32925 & 39 & 1947 & 41 \\
\hline \multicolumn{7}{|l|}{ Initial GCS } \\
\hline 15 & 78078 & 86.7 & 73856 & 87 & 4222 & 89 \\
\hline \multicolumn{7}{|l|}{ Initial pain score } \\
\hline no pain & 33293 & 37 & 31281 & 37 & 2012 & 42 \\
\hline $1-3$ & 15544 & 17.3 & 14850 & 17 & 694 & 15 \\
\hline $4-6$ & 21877 & 24.3 & 21026 & 25 & 851 & 18 \\
\hline $7-10$ & 19372 & 21.5 & 18167 & 21 & 1205 & 25 \\
\hline \multicolumn{7}{|l|}{ WCCI } \\
\hline 0 & 27291 & 30.3 & 25812 & 30 & 1479 & 31 \\
\hline $1-2$ & 46565 & 51.7 & 44120 & 52 & 2445 & 51 \\
\hline 3 and above & 16230 & 18 & 15392 & 18 & 838 & 18 \\
\hline \multicolumn{7}{|c|}{ LGA above median income for metropolitan Melbourne } \\
\hline No & 74068 & 82.2 & 70157 & 82 & 3911 & 82 \\
\hline \multicolumn{7}{|l|}{ Paramedic diagnosis } \\
\hline Dizzy & 6119 & 6.8 & 5654 & 6.6 & 465 & 9.8 \\
\hline Febrile & 4847 & 5.4 & 4369 & 5.1 & 478 & 10 \\
\hline $\begin{array}{l}\text { Gastrointestinal } \\
\text { disorder }\end{array}$ & 9444 & 10.5 & 8867 & 10 & 577 & 12 \\
\hline Pain & 64068 & 71.1 & 61207 & 72 & 2861 & 60 \\
\hline $\begin{array}{l}\text { Urinary tract } \\
\text { infection }\end{array}$ & 5608 & 6.2 & 5227 & 6.1 & 381 & 8 \\
\hline \multicolumn{7}{|l|}{ Treated } \\
\hline & 43432 & 48.2 & 41834 & 49 & 1598 & 34 \\
\hline \multicolumn{7}{|l|}{ Transported } \\
\hline & 80238 & 89.1 & 76024 & 89 & 4214 & 89 \\
\hline \multicolumn{7}{|c|}{ Highest dispatch code } \\
\hline 1 & 50542 & 56.1 & 50208 & 59 & 334 & 7 \\
\hline 2 & 27363 & 30.4 & 26015 & 31 & 1348 & 28 \\
\hline 3 & 12163 & 13.5 & 9086 & 11 & 3077 & 65 \\
\hline
\end{tabular}

Continued
Table 2 Continued

\begin{tabular}{|c|c|c|c|c|c|c|}
\hline & \multicolumn{2}{|l|}{ Total } & \multicolumn{2}{|c|}{$\begin{array}{l}\text { Direct } \\
\text { dispatch }(\mathrm{N}=85 \\
\text { 324) }\end{array}$} & \multicolumn{2}{|c|}{$\begin{array}{l}\text { Secondary } \\
\text { dispatch } \\
(\mathrm{N}=4762)\end{array}$} \\
\hline & $\mathbf{N}$ & $\%$ & $\mathbf{N}$ & $\%$ & $\mathbf{N}$ & $\%$ \\
\hline $\begin{array}{l}4 \text { (Non- } \\
\text { emergency } \\
\text { ambulance) }\end{array}$ & 18 & 0 & 15 & 0 & 3 & 0.1 \\
\hline \multicolumn{7}{|l|}{ Time of day } \\
\hline $\begin{array}{l}\text { Nightshift (1700- } \\
0700 \text { hours) }\end{array}$ & 40394 & 44.8 & 38255 & 45 & 2139 & 45 \\
\hline
\end{tabular}

GCS, Glasgow Coma Scale; LGA, Local Government Area; WCCl, Weighted Charlson Comorbidity Index.

so did the likelihood of treatment and transport. Patients who reported high levels of pain were up to four times more likely to be treated and 10 times more likely to be transported than those with lower pain levels. Febrile illness and UTI were the only paramedic diagnoses demonstrating a clinically significant increase in transportation rates when compared with patients with pain. Treatment and transport was more likely in patients with higher WCCI scores and abnormal vital signs.

\section{DISCUSSION}

This is the first study to investigate the appropriateness of secondary dispatch of older patients by comparing patients entering the secondary dispatch pathway to those directly dispatched. In order to ensure adequate sample size for comparison, the five most common paramedic diagnostic groups from the secondary dispatch pathway were matched to those from the direct dispatch pathway. Patient demographics and case characteristics were similar irrespective of dispatch pathway. Overall, ambulances were more likely to be dispatched on a Code 3 low-acuity response to secondary dispatch cases and these cases were half as likely to be treated by attending paramedics. Despite this, there was no difference in the likelihood of transport to hospital. While the transportation rates were high in both pathways, therefore indicating the ambulance dispatch was appropriate, the lack of treatment and low-acuity dispatch rates suggest many patients receiving a secondary dispatch may be suitable for alternative care or hospital transport arrangements.

Ambulance services, like EDs, are experiencing excess demand beyond that expected by changes in population, potentially compromising the outcomes of high-acuity patients requiring urgent medical attention. ${ }^{10} 15$ In the $\mathrm{ED}$, older patients comprise the largest proportion of attendances ${ }^{17}$ and like ambulance presentations, the rate has increased over time and with age. ${ }^{418}$ it has been estimated that up to a quarter of older patients present to ED with potentially avoidable conditions, ${ }^{71920}$ and many presentations are believed to have been precipitated by 'non-clinical' issues. ${ }^{15} 21$ 'Non-clinical' issues include things such as longterm functional decline, social isolation or suspicion of an 
Table 3 Comparison of treatment and transport rates for paramedic diagnosis between direct dispatch and secondary dispatch patients $\mathrm{N}=90086$

\begin{tabular}{|c|c|c|c|c|c|c|c|c|c|c|}
\hline & & & Treated & $=43432)$ & & & Transpc & $\operatorname{ted}(\mathrm{N}=$ & 30 238) & \\
\hline & Total & & $\begin{array}{l}\text { Direct a } \\
\text { dispatc }\end{array}$ & $\begin{array}{l}\text { ulance } \\
l=41834)\end{array}$ & $\begin{array}{l}\text { Seco } \\
\text { dispa }\end{array}$ & $\begin{array}{l}\text { nbulance } \\
\text { 598) }\end{array}$ & $\begin{array}{l}\text { Direct } \\
\text { ambula } \\
\text { dispatc } \\
\text { 024) }\end{array}$ & $(\mathrm{N}=76$ & $\begin{array}{l}\text { Secor } \\
\text { ambu } \\
\text { dispa }\end{array}$ & $\begin{array}{l}y \\
(N=4214)\end{array}$ \\
\hline $\begin{array}{l}\text { Paramedic diagnostic } \\
\text { category }\end{array}$ & $\mathbf{N}$ & $\%$ & $\mathbf{N}$ & $\%$ & $\mathbf{N}$ & $\%$ & $\mathbf{N}$ & $\%$ & $\mathbf{N}$ & $\%$ \\
\hline Dizzy & 6119 & 6.8 & 1285 & 23 & 70 & 15 & 4751 & 84 & 393 & 84.5 \\
\hline Febrile & 4847 & 5.4 & 1082 & 25 & 83 & 17 & 3863 & 88 & 431 & 90.2 \\
\hline Urinary tract infection & 5608 & 6.2 & 1024 & 20 & 80 & 21 & 4642 & 89 & 347 & 91.1 \\
\hline
\end{tabular}

abusive environment that can make older patients unsuitable for paramedics to leave at home, even in the absence of any medically urgent problem. ${ }^{21}$ EDs are not an ideal setting and can lack the necessary resources to provide management for many non-clinical issues, ${ }^{15}$ often resulting in longer than necessary ED stays ${ }^{18}$ and unnecessary admission. ${ }^{22}$ Furthermore, many of these issues may be predictable days or even months before and with adequate community support plans, contact with emergency care pathways can be avoided.

The similarity in transportation rate despite the difference in treatment of secondary dispatch cases indicates that attending paramedics viewed these patients as unsuitable to be left at home or referred to alternative care pathways. However, paramedic records do not record whether patients were transported due to a clinical or non-clinical need, and it is not known whether they would have transported these patients had viable alternatives been available. Nonetheless, the low paramedic treatment rates suggest that dispatching emergency ambulances might not be the most appropriate pathway for these patients, particularly in settings where alternative community care or medical transportation services are available.

It is important that the development of any triaging or clinical care services provide for patients seeking assistance for non-clinical problems and clinical problems that may not need an emergency response. Often, in considering the safety and welfare of older patients, they are transported to hospital due to lack of alternatives; however, a well-developed secondary telephone triage system with appropriate alternative care pathways could offer support for patients with non-clinical issues and medical care pathways for those with clinical problems. These pathways should comprise a network of community-based resources that interact with each other to benefit patients, and to provide good continuity of care by ultimately informing a patient's primary care provider of their care.

Patients presenting with pain are one such group who are often treated, yet may benefit from alternative care pathways. The findings of this study support those of others whereby patients are referred for secondary dispatch because an exacerbation of pain is identified during secondary triage. ${ }^{10} 13$ The subsequent high correlation between pain score and treatment was expected because paramedics have a range of pharmacological interventions to address pain, and pain reduction is often a key performance indicator. However, this intervention does not necessarily indicate that an emergency ambulance was the most appropriate care for these patients. While the secondary telephone triage service used in this study has a range of alternative care providers who can provide pain medication, none specialise specifically in pain management, particularly for patients presenting with chronic pain exacerbation. Further research is required to allow for a more specific assessment of pain and a patient's immediate needs in addition to the triaging clinicians attitudes and educational needs in assessing for, and managing chronic pain. The feasibility and benefit of engaging with community services specialising in pain management that can respond within a short timeframe needs to be investigated in order to avoid entry to the emergency care pathways for suitable patients.

Further investigation of the hospital outcomes of older patients transported by ambulance should occur to identify any unmet need for this group and improve alternative care pathways specifically for older patients to avoid unnecessary emergency ambulance and ED presentation. Also, further work should be done to improve the secondary triage process to adequately identify and define clinical and non-clinical indicators that can further differentiate older patients and match them with the most appropriate alternative care pathways. Finally, research is required to understand the triaging clinician's knowledge relating to the care and outcomes of older patients into the ED, to determine whether further education would be beneficial to improve their assessment and care pathway triage accuracy.

\section{LIMITATIONS}

This study was a retrospective analysis of data entered by clinicians at the time of patient contact and so accuracy of 
Table 4 Adjusted and unadjusted OR results for association between direct dispatch and secondary dispatch for treatment and transport

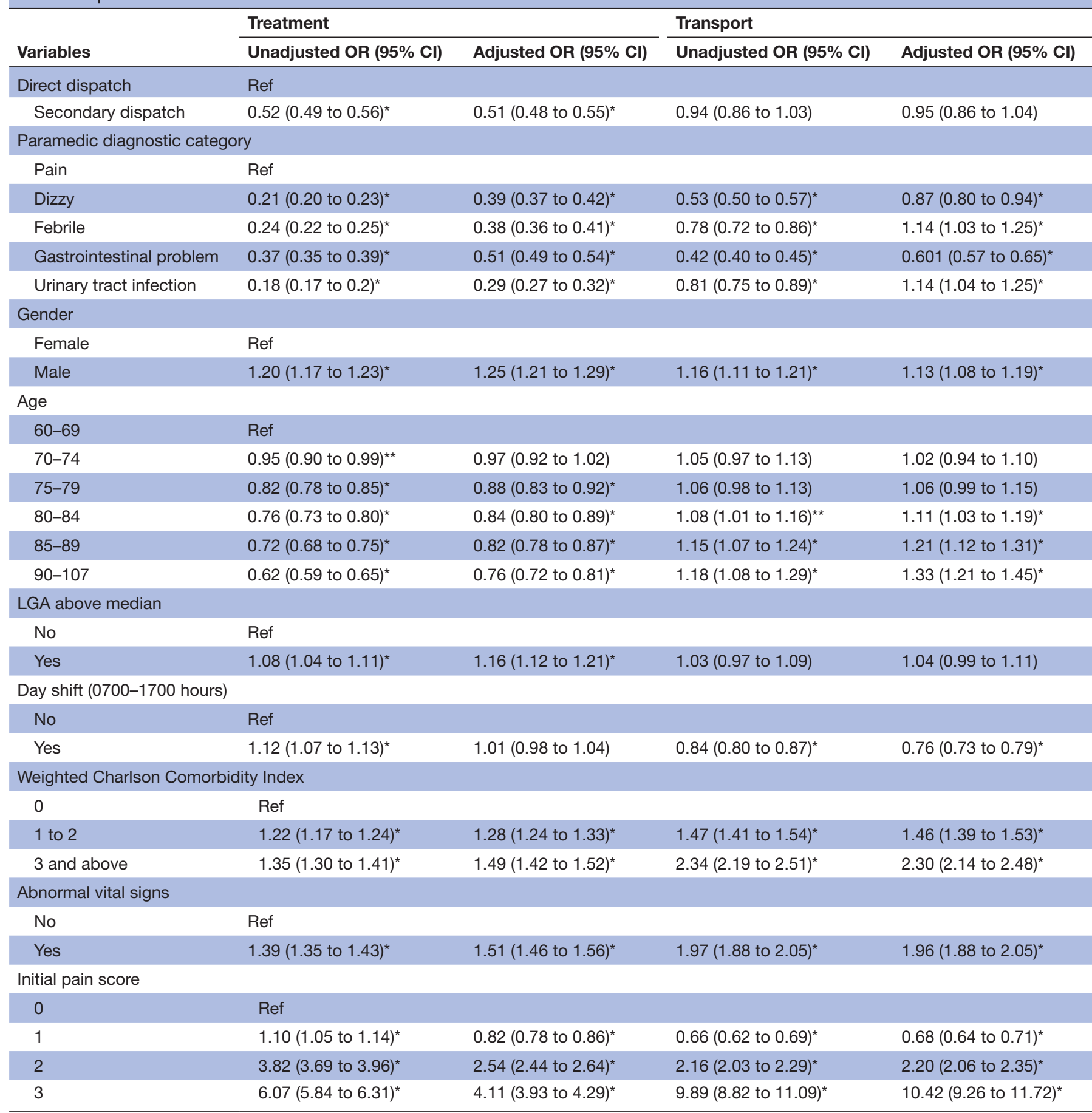

${ }^{* *} p<0.001 ;{ }^{*} p<0.005$

LGA, Local Government Area.

inputs may be influenced by ePCR structure, clinician biases and time pressures. Data were only available for metropolitan regions and thus not representative of regional and rural areas. While the primary triage system used in this study is widely used internationally, the secondary telephone triage system used may differ from others. This includes differences in operational structure, triaging and alternative care pathways which may alter the triage outcomes and limit the generalisability of the results. This is also true for emergency ambulance operations. Ambulance services internationally employ paramedics with varying skill levels and levels of autonomy. This will result in different approaches to management and possibly result in different outcomes for other jurisdictions. Finally, the data used in this study was from 2009 to 2012 potentially allowing for changes in practice to have occurred since. Despite this, it was felt the 
comparison of care pathways for older patients remains relevant given the secondary telephone triage process is not yet embedded in all unscheduled health service contact management systems.

\section{CONCLUSION}

Secondary triage could identify patients who would ultimately be transported to an ED. However, the lower paramedic treatment rates suggest many secondary dispatch patients may not have required emergency ambulance transportation and may have been suitable for referral to alternative low-acuity transport or referral options.

\section{Acknowledgements Stuart Howell for his statistical support.}

Contributors KE: study conception, prepared secondary datasets, data analysis and wrote the paper. DN: study conception, data analysis and wrote the paper. RD: study conception, consulted on the data analysis, emergency medicine consultant and edited the paper. JAL: discussed core ideas to study, consultation on older person research and emergency services usage, edited the paper. PC: discussed core ideas to study, emergency medicine consultant and emergency services usage consultant, edited the paper. KS: discussed core ideas to study, oversaw the data extraction, consulted on the data analysis and edited the paper.

Funding The authors have not declared a specific grant for this research from any funding agency in the public, commercial or not-for-profit sectors.

Competing interests All authors have completed the ICMJE uniform disclosure form at www.icmje.org/coi_disclosure.pdf and declare: KE has previously worked in the Ambulance Victoria Referral Service and is an operation intensive care paramedic for Ambulance Victoria. Professor Karen Smith is the Director of the Ambulance Victoria Centre for Research and Evaluation. The remaining authors declare no financial relationships with any organisations that might have an interest in the submitted work in the previous three years. No other relationships or activities that could appear to have influenced the submitted work.

Patient and public involvement Patients and/or the public were not involved in the design, or conduct, or reporting, or dissemination plans of this research.

Patient consent for publication Not required.

Ethics approval Ethics approval was granted by the Monash University Human Research Ethics Committee (16379).

Provenance and peer review Not commissioned; externally peer reviewed.

Data availability statement No additional data available.

Open access This is an open access article distributed in accordance with the Creative Commons Attribution Non Commercial (CC BY-NC 4.0) license, which permits others to distribute, remix, adapt, build upon this work non-commercially, and license their derivative works on different terms, provided the original work is properly cited, appropriate credit is given, any changes made indicated, and the use is non-commercial. See: http://creativecommons.org/licenses/by-nc/4.0/.

\section{ORCID iDs}

Kathryn Eastwood http://orcid.org/0000-0001-8442-4617

Dhanya Nambiar http://orcid.org/0000-0002-9351-964X

Judy A Lowthian http://orcid.org/0000-0002-9780-5256

Peter Cameron http://orcid.org/0000-0002-1443-557X

Karen Smith http://orcid.org/0000-0002-9057-0685

\section{REFERENCES}

1 Eastwood K, Morgans A, Smith K, et al. A novel approach for managing the growing demand for ambulance services by low-acuity patients. Australian Health Rev 2015.
2 Eastwood K, Morgans A, Stoelwinder J, et al. The appropriateness of low-acuity cases referred for emergency ambulance dispatch following ambulance service secondary telephone triage: a retrospective cohort study. PLoS One 2019;14:e0221158.

3 Eastwood K, Smith K, Morgans A, et al. Appropriateness of cases presenting in the emergency department following ambulance service secondary telephone triage: a retrospective cohort study. BMJ Open 2017;7:e016845.

4 Lowthian JA, Jolley DJ, Curtis AJ, et al. The challenges of population ageing: accelerating demand for emergency ambulance services by older patients, 1995-2015. Med J Aust 2011;194:574-8.

5 Marks PJ, Daniel TD, Afolabi O, et al. Emergency (999) calls to the ambulance service that do not result in the patient being transported to hospital: an epidemiological study. Emerg Med J 2002;19:449-52.

6 Dwyer R, Gabbe B, Tran TD, et al. Patterns of emergency ambulance use, 2009-13: a comparison of older people living in residential aged care facilities and the community. Age Ageing 2018;47:615-9.

7 Gruneir A, Silver MJ, Rochon PA. Emergency department use by older adults: a literature review on trends, appropriateness, and consequences of unmet health care needs. Med Care Res Rev 2011;68:131-55

8 Finn JC, Flicker L, Mackenzie E, et al. Interface between residential aged care facilities and a teaching hospital emergency department in Western Australia. Med J Aust 2006;184:432-5.

9 Mason S, Wardrope J, Perrin J. Developing a community paramedic practitioner intermediate care support scheme for older people with minor conditions. Emerg Med J 2003;20:196-8.

10 Eastwood K, Morgans A, Stoelwinder J, et al. Patient and case characteristics associated with 'no paramedic treatment' for lowacuity cases referred for emergency ambulance dispatch following a secondary telephone triage: a retrospective cohort study. Scand J Trauma Resusc Emerg Med 2018;26:8.

11 Australian Bureau of Statistics. 3218.0 Regional population growth Australia 2012-2013 Canberra: Australian government, 2015. Available: http://www.abs.gov.au/ausstats/abs@.nsf/Products/3218. 0 2012-13 Main+Features Victoria?OpenDocument\#PARALINK3 [Accessed 3 Feb 2016].

12 Australian Bureau of Statistics. Greater Melbourne (GCCSA) Canberra: Australian government, 2015. Available: http://stat.abs. gov.au/itt/r.jsp?RegionSummary\&region=2GMEL\&dataset=ABS_ REGIONAL_ASGS\&geoconcept=REGION\&measure=MEASURE\& datasetASGS=ABS_REGIONAL_ASGS\&datasetLGA=ABS REGIONAL_LGA\&regionLGA=REGION\&regionASGS=REGION [Accessed 22 Mar 2016].

13 Dale J, Higgins J, Williams S, et al. Computer assisted assessment and advice for 'non-serious' 999 ambulance service callers: the potential impact on ambulance despatch. Emerg Med $\mathrm{J}$ 2003;20:178-83.

14 Hodell EM, Sporer KA, Brown JF. Which emergency medical dispatch codes predict high prehospital nontransport rates in an urban community? Prehosp Emerg Care 2014;18:28-34.

15 Faulkner D, Law J. The 'unnecessary' use of emergency departments by older people: findings from hospital data, hospital staff and older people. Aust Health Rev 2015;39:544-51.

16 Andrew E, Nehme Z, Cameron P, et al. Drivers of increasing emergency ambulance demand. Prehosp Emerg Care 2020;24:385.

17 Šteinmiller J, Routasalo P, Suominen T. Older people in the emergency department: a literature review. Int J Older People Nurs 2015;10:284-305.

18 Lowthian J, Curtis A, Stoelwinder J, et al. Emergency demand and repeat attendances by older patients. Intern Med J 2013;43:554-60.

19 Gulacti U, Lok U, Celik M, et al. The ED use and non-urgent visits of elderly patients. Turk J Emerg Med 2016;16:141-5.

20 Codde J, Frankel J, Arendts G, et al. Quantification of the proportion of transfers from residential aged care facilities to the emergency department that could be avoided through improved primary care services. Australas J Ageing 2010;29:167-71.

21 Cone DC, Schmidt TA, Mann NC, et al. Developing research criteria to define medical necessity in emergency medical services. Prehosp Emerg Care 2004;8:116-25.

22 Silvester KM, Mohammed MA, Harriman P, et al. Timely care for frail older people referred to hospital improves efficiency and reduces mortality without the need for extra resources. Age Ageing 2014;43:472-7

23 Charlson M, Szatrowski TP, Peterson J, et al. Validation of a combined comorbidity index. J Clin Epidemiol 1994;47:1245-51. 